\title{
Prevalence of pneumonia and its associated factors among under-five children in East Africa: a systematic review and meta-analysis
}

Biruk Beletew*, Melaku Bimerew, Ayelign Mengesha, Mesfin Wudu and Molla Azmeraw

\begin{abstract}
Background: Pneumonia is defined as an acute inflammation of the Lungs' parenchymal structure. It is a major public health problem and the leading cause of morbidity and mortality in under-five children especially in developing countries. In 2015, it was estimated that about 102 million cases of pneumonia occurred in under-five children, of which 0.7 million were end up with death. Different primary studies in Eastern Africa showed the burden of pneumonia. However, inconsistency among those studies was seen and no review has been conducted to report the amalgamated magnitude and associated factors. Therefore, this review aimed to estimate the national prevalence and associated factors of pneumonia in Eastern Africa
\end{abstract}

Methods: Using PRISMA guideline, we systematically reviewed and meta-analyzed studies that examined the prevalence and associated factors of pneumonia from PubMed, Cochrane library, and Google Scholar. Heterogeneity across the studies was evaluated using the $Q$ and the $I^{2}$ test. A weighted inverse variance randomeffects model was applied to estimate the national prevalence and the effect size of associated factors. The subgroup analysis was conducted by country, study design, and year of publication. A funnel plot and Egger's regression test were used to see publication bias. Sensitivity analysis was also done to identify the impact of studies.

Result: A total of 34 studies with 87, 984 participants were used for analysis. The pooled prevalence of pneumonia in East Africa was 34\% (95\% Cl; 23.80-44.21). Use of wood as fuel source (AOR $=1.53 ; 95 \% \mathrm{Cl}: 1.30-1.77 ;\left.\right|^{2}=0.0 \% ; P=$ $0.465)$, cook food in living room ( $\left.A O R=1.47 ; 95 \% \mathrm{Cl}: 1.16-1.79 ;\left.\right|^{2}=0.0 \% ; P=0.58\right)$, caring of a child on mother during cooking $\left(A O R=3.26 ; 95 \% \mathrm{Cl}: 1.80-4.72 ; \mathrm{I}^{2}=22.5 \% ; P=0.26\right)$, Being unvaccinated $\left(\mathrm{AOR}=2.41 ; 95 \% \mathrm{Cl}: 2.00-2.81 ; \mathrm{I}^{2}=\right.$ $51.4 \% ; P=0.055)$, Child history of Acute Respiratory Tract Infection (ARTI) $\left(A O R=2.62 ; 95 \% \mathrm{Cl}: 1.68-3.56 ; I^{2}=11.7 \%\right.$; $P=0.337$ ) were identified factors of pneumonia.

Conclusion: The prevalence of pneumonia in Eastern Africa remains high. This review will help policy-makers and program officers to design pneumonia preventive interventions.

Keywords: Pneumonia, Eastern-Africa, Under five children, Indicator Cluster Surveys (MICS) Child Health/ Pneumonia.2017

\footnotetext{
* Correspondence: birukkelemb@gmail.com

Department of Nursing, College of Health Sciences, Woldia University,

P.O.Box 400, Woldia, Ethiopia
}

(c) The Author(s). 2020 Open Access This article is licensed under a Creative Commons Attribution 4.0 International License, which permits use, sharing, adaptation, distribution and reproduction in any medium or format, as long as you give appropriate credit to the original author(s) and the source, provide a link to the Creative Commons licence, and indicate if changes were made. The images or other third party material in this article are included in the article's Creative Commons licence, unless indicated otherwise in a credit line to the material. If material is not included in the article's Creative Commons licence and your intended use is not permitted by statutory regulation or exceeds the permitted use, you will need to obtain permission directly from the copyright holder. To view a copy of this licence, visit http://creativecommons.org/licenses/by/4.0/ The Creative Commons Public Domain Dedication waiver (http://creativecommons.org/publicdomain/zero/1.0/) applies to the data made available in this article, unless otherwise stated in a credit line to the data. 


\section{Background}

Pneumonia is defined as an acute inflammation of the Lungs' parenchymal structure. It can be classified based on place of acquisition: as community acquired or hospital acquired; based on its causative agents/ mechanism as bacterial, viral, fungal, Aspiration, or ventilatorassociated pneumonia; based on the anatomy of the lungs involved as lobar pneumonia, bronchial pneumonia or acute interstitial pneumonia; and on the basis of its clinical severity as "no pneumonia", "pneumonia" or "severe pneumonia" [1-3].

Under-five children are more vulnerable to pneumonia and pneumonia remains the leading cause of morbidity and mortality in those children [4]. According to a global estimate made in 2000, approximately 156 million cases of pneumonia had occurred each year in underfive children, of which 151 million episodes were in the developing countries and about 1.2 million of them were end up in death. South-east Asia and Africa were the two continents with high magnitude of childhood pneumonia, having an estimated of 61 million and 35 million annual cases of pneumonia in under-five children respectively [5]. The magnitude of under-five pneumonia was decreased to 120 million (with 0.88 million deaths) in 2010 and to 102 million (with 0.7 million deaths) in 2015 globally. These decrement was due to decrease in the magnitude of its key risk factors, increasing socioeconomic development and preventive interventions, improved access to care, and quality of care in hospitals. Despite this progress, pneumonia is still a major public health problem for children especially in developing countries [4].

Globally, many researches had been conducted to identify risk factors of pneumonia. Despite the inconsistency of findings, low birth weight, malnutrition, indoor air pollution, parental smoking, being unvaccinated, overcrowding, lack of separate kitchen, being not on exclusive breast feeding, and maternal education were identified as factors associated with occurrence of pneumonia in under-five children [6-9].

Besides, in East African countries different researchers had tried to investigate the magnitude of pneumonia in under-five children and have reported a prevalence ranges from $5.5 \%$ [10] up to $89.8 \%$ [11]. They had also identified risk factors for pneumonia among under-five children. But, reported finding lack consistency and as per the investigators knowledge there is no a systematic review and meta-analysis conducted to address these inconsistent findings reported from East African countries. Moreover, assessing the magnitude of pneumonia and identifying its associated factors for risk based diagnosis of pneumonia contribute in better interventions and helps to reduce the higher burden of pneumonia in under-five children. Hence, this systematic review and meta-analysis was conducted to assess the magnitude of pneumonia and its associated factors among under-five children in East Africa.

\section{Methods \\ Reporting}

The results of this review were reported based on the Preferred Reporting Items for Systematic Review and MetaAnalysis statement (PRISMA) guideline (Supplementary file-PRISMA checklist) and, it is registered in the Prospero database: (PROSPERO 2019: CRD42019136707) Available from https://www.crd.york.ac.uk/PROSPERO/\#myprosperoID $=$ CRD42019136707.

\section{Searching strategy and information sources}

We identified studies providing data on the prevalence of and potential risk factors of pneumonia among under-five children, with the search focused on Eastern Africa from PubMed, Cochrane library, and Google Scholar. The search included $\mathrm{MeSH}$ terms and keywords, combinations, and snowball searching in references list of papers found through the data base search to retrieve additional articles. Articles with incomplete reported data were handled through contacting corresponding authors. Unpublished studies were retrieved from the official websites of international and local organizations and universities. The search was performed by keywords, medical subject headings (MeSH) terms. We used the search terms independently and/or in combination using "OR" or "AND". The core search terms and phrases were "under five", "children", "child", "infant", and "pneumonia", "respiratory infection", causes, risk factors, determinants, associated factors, predictors and Eastern Africa. The search strategies were developed using different Boolean operators. Remarkably, to fit advanced PubMed database, the following search strategy was applied: (prevalence OR magnitude OR epidemiology) AND (causes OR determinants OR associated factors OR predictors OR risk factors) AND (children [MeSH Terms] OR under five OR child OR childhood) AND (pneumonia [MeSH Terms] OR respiratory tract infection) AND Eastern Africa. We also screened at the reference lists of the remaining papers to identify additional relevant studies to this review.

\section{Study selection / eligibility criteria}

Retrieved studies were exported to reference manager software, Endnote version 8 to remove duplicate studies. Two investigators (BB and AM) independently screened the selected studies using their titles and abstracts before retrieval of full-text papers. We used pre-specified inclusion criteria to further screen the full-text articles. Disagreements were discussed during a consensus meeting with other reviewers (MW and $\mathrm{MB}$ ) for the final 
selection of studies to be included in the systematic review and meta-analysis.

\section{Inclusion and exclusion criteria}

All observational studies (cross-sectional, case-control, and cohort studies) were included. Those studies had reported the prevalence and/or at least one associated factors of pneumonia among under-five children and published in English language from 2000 up to 2019 in Eastern Africa were considered. A consideration was extended to unpublished work among children under five were also considered. Citations without abstract and/or full-text, anonymous reports, editorials, and qualitative studies were excluded from the analysis. Furthermore, researches which did not report our results of interest were excluded. Regarding inclusion and exclusion criteria of included studies, children below 59 months of age with mother / care giver visiting out patients department during data collection period were included. Severely sick child need life treating intervention and whose mother / care givers refused were excluded from the study.

\section{Quality assessment}

Duplicate articles were removed using Endnote (version X8) after combining the Database search results. The Joanna Briggs Institute (JBI) quality appraisal checklist was used [12, 13]. Four independent authors appraised the quality of the studies. The appraisal was repeated by exchanging with each other. Thus, one paper was appraised by two Authors. Any disagreement between the reviewers was solved by taking the mean score of the two reviewers. Studies were considered as low risk or good quality when it scored 5 and above for all designs (cross sectional, case control, and cohort) and were included $[12,13]$ whereas the score was 4 and below the studies considered as high risk or poor quality and was not included.

\section{Data extraction}

The authors developed data extraction form on the excel sheet which includes author name, year of publication, study country, study design, sample size, prevalence of pneumonia, and categories of factors reported. The data extraction sheet was piloted using 4 papers randomly. The extraction form was adjusted after piloted the template. Two of the authors extracted the data using the extraction form in collaboration. The third and fourth authors check the correctness of the data independently. Any disagreements between reviewers were resolved through discussions with a third reviewer and fourth reviewer if required. The mistyping of data was resolved through crosschecking with the included papers. If we got incomplete data, we excluded the study after two attempts were made to contact the corresponding author by email.

\section{Outcome measurement}

Pneumonia was considered when under five children with cough and/or difficulty of breathing, have fast breathing and/or chest indrawing and suggestive X-ray findings $[14,15]$.

\section{Statistical analysis}

After the data was extracted using Microsoft Excel format we imported the data to STATA version 14.0 statistical software for further analysis. Using the binomial distribution formula, Standard error was calculated for each study. We pooled the overall magnitude estimates of pneumonia by a random effect meta-analysis [16]. The pooled prevalence of pneumonia with $95 \%$ CI was presented using forest plots and Odds ratio (OR) with 95\% CI was also presented in forest plot to show the associated factors of pneumonia. We examined the heterogeneity between the studies using Cochrane's $\mathrm{Q}$ statistics (Chi-square), invers variance (I2) and $p$-values [17].

In this study, the $\mathrm{I}^{2}$ statistic value of zero indicates true homogeneity, whereas the value 25,50 , and $75 \%$ represented low, moderate and high heterogeneity respectively $[18,19]$. For the data identified as heterogeneous, we conducted our analysis by random-effects model analysis. In addition subgroup analysis was done by the study country, design, and year of publication. When statistical pooling is not possible, nonpooled data was presented in table form. Sensitivity analysis was employed to see the effect of a single study on the overall estimation. Publication bias was checked by funnel plot and more objectively through Egger's regression test [20].

\section{Result}

Study selection

A total of 6879 studies were identified using electronic searches (through Databases searching $(n=6867)$ ) and other sources $(n=12))$ that were conducted from 2000 up to 2019. After duplication removed, a total of 3150 articles remained (3729 duplicated). Finally, 200 studies were screened for full-text review and, 34 articles with ( $n=87,984$ patients) were selected for the prevalence and/ or associated factors analysis (Fig.1).

\section{Characteristics of included studies}

Table 1 summarizes the characteristics of the 34 included studies in the systematic review and metaanalysis [10, 11, 21-37, 39-52]. 16 studies were found in Ethiopia [10, 22-36], 8 in Kenya [11, 37, 39-43], 2 in Uganda [51, 52],1 Eritrea [21], 1 in Somali [44],4 Sudan $[45-48], 2$ Tanzania $[49,50]$. 


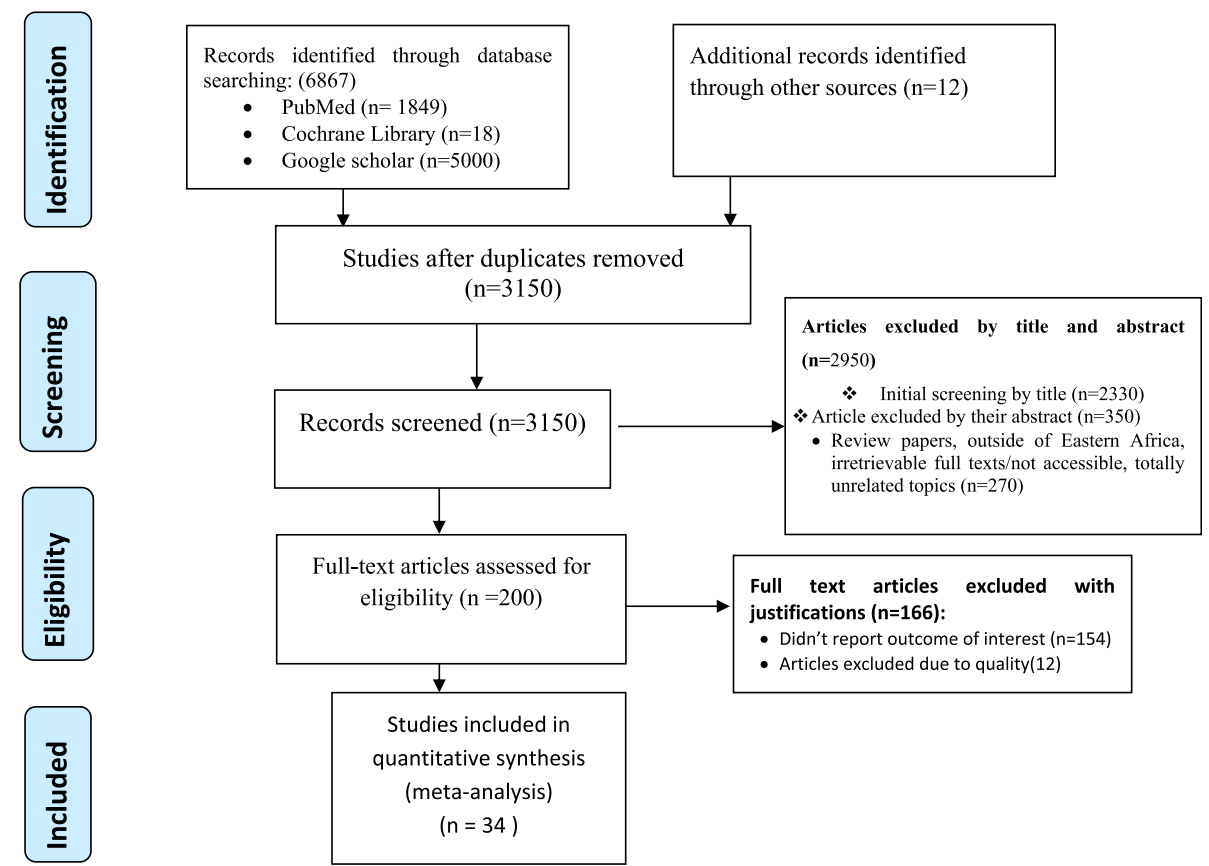

Fig. 1 PRISMA flow diagram showed the results of the search and reasons for exclusion

23 studies were cross-sectional, while the others used either case-control $(n=9)$ or cohort $(n=2)$ study design. Most of the studies 23/34(70.5\%) were published between 2015 and 2019. The studies included participants, ranging from $40[45]$ to 73,778 [44] (Table 1).

\section{Meta-analysis}

Prevalence of pneumonia among fewer than five children in Ethiopia

Most of the studies $(n=23)$ had reported the prevalence of pneumonia $[10,11,21-25,28,29,33-36,41-47,50-$ 52]. The prevalence of pneumonia were ranged from $5.5 \%$ [10] up to $89.8 \%$ [11]. The random-effects model analysis from those studies revealed that, the pooled prevalence of pneumonia in East Africa was found to be 34\% (95\%CI; 23.80-44.21; $\mathrm{I}^{2}=99.4 \% ; p<0.001$ ) (Fig.2).

\section{Subgroup analysis of the prevalence of pneumonia in eastern Africa}

The subgroup analysis was done through stratified by country, study design, and year of publication. Based on this, the prevalence of pneumonia among under five children was found to be 29 in Eritrea, 22.62 in Ethiopia, 64.3 in Kenya, 29.71 in Sudan, 22 in Tanzania, and 32.72 in Uganda (Supplementary Fig. 1 and Table 2). Based on the study design, the prevalence of pneumonia was found to be 32.33 in cross-sectional studies, $55.68 \%$ in cohort studies and 22.6 in case control studies (Supplementary Fig. 2 and Table 2). Based on the year of publication, the prevalence of pneumonia was found to be
33.4 from 2000 to 2015, while it was 34.29 from studies conducted from 2016 to 2019(Supplementary Fig. 3, Table 2).

\section{Sensitivity analysis}

We employed a leave-one-out sensitivity analysis to identify the potential source of heterogeneity in the analysis of the prevalence of pneumonia in Eastern Africa. The results of this sensitivity analysis showed that our findings were not dependent on a single study. Our pooled estimated prevalence of pneumonia varied between 31.38(22.93-39.83) [11] and 35.3(25.13-45.49) [10] after deletion of a single study (Supplementary Fig. 4).

\section{Publication Bias}

We have also checked publication bias and a funnel plot showed symmetrical distribution. Egger's regression test $p$-value was 0.63 , which indicated the absence of publication bias (Supplementary Fig. 5).

\section{Factors associated with pneumonia}

Out of the total included studies 18 studies [10, 22-28, $30-35,37,39,40,43]$ revealed the factors associated with pneumonia among under five children in Eastern Africa (Table 3).

\section{Use of wood as fuel source}

Eight studies found significant association between use of wood as fuel source and pneumonia among under five 
Table 1 Distribution of studies on the prevalence and determinants of pneumonia among under five children in East Africa, 2000-2019

\begin{tabular}{|c|c|c|c|c|c|c|}
\hline Author/Reference & Year & Country & Study design & Sample size & Prevalence (\%) & Quality score \\
\hline Shah et al [21] & 2012 & Eritrea & Cross-sectional & 1502 & 29 & $5 / 8$ \\
\hline Negash et al [22] & 2019 & Ethiopia & Cohort & 362 & 21.5 & $9 / 11$ \\
\hline Abaye et al [23] & 2019 & Ethiopia & Cross-sectional & 477 & 18.4 & $6 / 8$ \\
\hline Lema et al [24] & 2019 & Ethiopia & Cross-sectional & 344 & 17.7 & $7 / 8$ \\
\hline Fekadu et al [25] & 2014 & Ethiopia & Cross-sectional & 286 & 16.1 & $7 / 8$ \\
\hline Dadi et al [26] & 2014 & Ethiopia & Case control & 356 & & $7 / 8$ \\
\hline Geleta et al [27] & 2016 & Ethiopia & case control & 382 & & $8 / 8$ \\
\hline Shibre et al [10] & 2015 & Ethiopia & Cross-sectional & 458 & 5.5 & $6 / 8$ \\
\hline Tegenu et al [28] & 2018 & Ethiopia & Cross-sectional & 306 & 28.1 & $5 / 8$ \\
\hline Abuka et al [29] & 2017 & Ethiopia & Cross-sectional & 206 & 33.5 & $7 / 8$ \\
\hline Workineh et al [30] & 2017 & Ethiopia & Case control & 558 & & $7 / 10$ \\
\hline Markos et al [31] & 2019 & Ethiopia & Case control & 435 & & $7 / 10$ \\
\hline Gedefaw et al [32] & 2015 & Ethiopia & Case control & 244 & & $8 / 10$ \\
\hline Tadesse et al [33] & 2015 & Ethiopia & Cross-sectional & 150 & 26.7 & $8 / 8$ \\
\hline Adhanom et al [34] & 2019 & Ethiopia & Cross-sectional & 252 & 43.7 & $5 / 8$ \\
\hline Lenda et al [35] & 2018 & Ethiopia & Cross-sectional & 458 & 17.6 & $8 / 8$ \\
\hline Deribew et al [36] & 2007 & Ethiopia & case control & 168 & 22.6 & $9 / 10$ \\
\hline MANYA et al [37] & 2005 & Kenya & case control & 188 & & $7 / 10$ \\
\hline Keter et al [38] & 2015 & Kenya & Cross-sectional & 422 & 67.1 & $6 / 8$ \\
\hline Onyango et al [39] & 2012 & Kenya & case control & 206 & & $7 / 10$ \\
\hline Muthumbi et al [40] & 2017 & Kenya & Cross-sectional & 1483 & & $7 / 8$ \\
\hline Ndungu et al [41] & 2018 & Kenya & Cross-sectional & 323 & 74.3 & $6 / 8$ \\
\hline Walekhwa et al [42] & 2019 & Kenya & Cross-sectional & 206 & 20.39 & $7 / 8$ \\
\hline Sikolia et al [43] & 2002 & Kenya & Cross-sectional & 300 & 69.7 & $6 / 8$ \\
\hline Ásbjörnsdóttir et al [11] & 2012 & Kenya & Cohort & 365 & 89.8 & $10 / 11$ \\
\hline Kinyoki et al [44] & 2017 & Somalia & Cross-sectional & 73,778 & 17 & $6 / 8$ \\
\hline Gritly et al [45] & 2018 & Sudan & Cross-sectional & 40 & 65 & $7 / 8$ \\
\hline Salih et al [46] & 2014 & Sudan & Cross-sectional & 195 & 10.32 & $5 / 8$ \\
\hline Gabbad et al [47] & 2014 & Sudan & Cross-sectional & 282 & 20.2 & $7 / 8$ \\
\hline Deng et al [48] & 2019 & Sudan & case control & 108 & & $8 / 10$ \\
\hline Ndosa et al [49] & 2015 & Tanzania & Cross-sectional & 12.3 & & $5 / 8$ \\
\hline Lugangira et al [50] & 2017 & Tanzania & Cross-sectional & 1130 & 22 & $8 / 8$ \\
\hline Lindstrand et al [51] & 2018 & Uganda & Cross-sectional & 1723 & 56 & $6 / 8$ \\
\hline Tuhebwe et al [52] & 2014 & Uganda & Cross-sectional & 278 & 9.4 & $7 / 8$ \\
\hline
\end{tabular}

children. Of these the highest risk factor, $\mathrm{AOR}=7.41$ (95\% CI: 2.75, 19.95), Fekadu et al [25] and lowest risk factor AOR $=1.15(0.47,1.88)$,Negash et al [22] compared to those who use non wood items as a source of fuel (Table 3). Regarding heterogeneity test, Galbraith plot showed homogeneity and combining the result of eight studies, the forest plot showed the overall estimate of AOR of using wood as fuel source was $1.53(95 \% \mathrm{C}$ I: $\left.1.30,1.77 ; \mathrm{I}^{2}=0.0 \% ; P=0.465\right)$. I-Squared $\left(\mathrm{I}^{2}\right)$ and $P$-value also showed homogeneity (Supplementary Fig. 6). Regarding publication bias, a funnel plot showed a symmetrical distribution. During the Egger's regression test, the $p$-value was 0.176 , which indicated the absence of publication bias (Supplementary Fig. 7).

We employed a leave-one-out sensitivity analysis to identify the potential source of heterogeneity in the analysis of the pooled estimate of using wood as fuel source as a risk factor of pneumonia in Eastern Africa. The results of this sensitivity analysis showed that our findings were not dependent on a single study. Our pooled estimate of using wood as fuel source varied between $1.409(95 \% \mathrm{CI}, 1.122-1.696)$ and 1.664 (95\% CI, 1.321- 


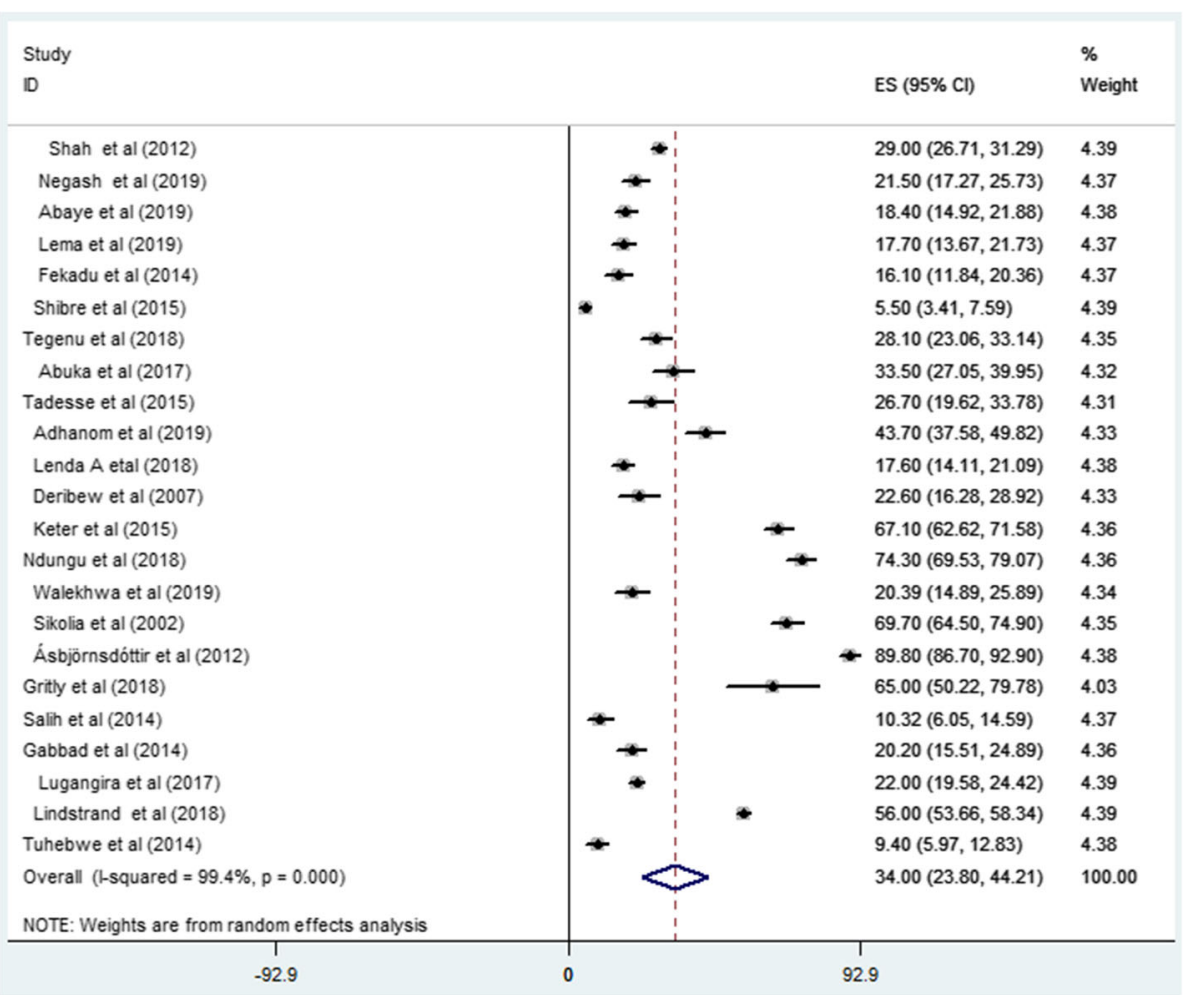

Fig. 2 Forest plot showing the pooled prevalence of pneumonia among under-five children in Eastern Africa from 2000 up to 2019

2.008) after deletion of a single study (Supplementary Fig. 8).

\section{Cooking food in living room}

Six studies found significant association between cooking food at living room and pneumonia among under five children. Of these the highest risk factors, $A O R=$ 3.27(1.4, 7.9) Tegenu et al [28] and lowest risk factor AOR $=1.35(0.3,0.99)$ Sikolia et al [43] compared to those who cook food at kitchen (Table 3). Regarding heterogeneity test for cooking food at in living room, Galbraith plot showed homogeneity and combining the result of six studies the forest plot showed the overall estimate of AOR of cooking food in living room was $1.47(95 \% \mathrm{CI}$ : $\left.1.16-1.79 ; \mathrm{I}^{2}=0.0 \% ; P=0.58\right) . \mathrm{I}$-Squared $\left(\mathrm{I}^{2}\right)$ and $P$-value also showed homogeneity (Supplementary Fig. 9). Regarding publication of bias for cooking food at home, the funnel plot analysis showed asymmetrical distribution. During the Egger's regression test, the $p$-value was 0.026 , which indicated the presence of publication bias (Supplementary Fig. 10). Trim and fill analysis was done, and 3 study were added and the total number of studies

Table 2 Subgroup analysis of the prevalence of pneumonia in Eastern Africa by country, design and year of publication

\begin{tabular}{llll}
\hline Variables & Characteristics & Pooled prevalence $(95 \% \mathrm{Cl})$ & $\mathrm{I}^{2}(\mathrm{P}$-value $)$ \\
\hline By country & Eritrea & $29.00(26.71-31.29)$ & - \\
& Ethiopia & $22.62(16.37-28.87)$ & $96 \%(<0.001)$ \\
& Kenya & $64.31(42.70-85.92)$ & $99.1 \%(<0.001)$ \\
& Sudan & $29.71(11.83-47.60)$ & $96.1 \%(<0.001)$ \\
& Tanzania & $22.00(19.58-24.42)$ & - \\
Bganda & $32.72(12.95-78.38)$ & $32.33(23.22-41.44)$ & $99.8 \%(<0.001)$ \\
& Cross-sectional & $55.68(-11.27-122.60)$ & $99.2 \%(<0.001)$ \\
Cosign & Cohort & $22.60(16.28-28.92)$ & $99.8 \%(<0.001)$ \\
By year of publication & Case control & $33.40(11.54-55.25)$ & - \\
& $2000-2015$ & $34.29(23.05-44.21)$ & $99.6 \%(<0.001)$ \\
\hline
\end{tabular}


Table 3 Factors associated with pneumonia in East Africa

\begin{tabular}{|c|c|c|c|c|c|}
\hline Variables & Odds ratio(95\%Cl) & Author (reference) & Year & Pooled AOR(95\%Cl) & $I^{2}(P$-value $)$ \\
\hline \multirow[t]{8}{*}{ Use of wood as fuel source } & $1.15(0.47,1.88)$ & Negash et al [22] & 2019 & $1.53(1.30,1.77)$ & $0.0 \%(0.465)$ \\
\hline & $2.1(0.58,6.98)$ & Lema et al [24] & 2019 & & \\
\hline & $7.41(2.75,19.95)$ & Fekadu et al [25] & 2014 & & \\
\hline & $1.49(0.32,6.36)$ & Shibre et al [10] & 2015 & & \\
\hline & $3.41(1.5,7.7)$ & Tegenu et al [28] & 2018 & & \\
\hline & $2.92(0.78,10.84)$ & Abuka et al [29] & 2017 & & \\
\hline & $1.78(0.28,1.09)$ & Onyango et al [39] & 2012 & & \\
\hline & $1.42(0.28,0.92)$ & Sikolia et al [43] & 2002 & & \\
\hline \multirow[t]{6}{*}{ Cook food in living room } & $2.12(0.76,5.92)$ & Lema et al [24] & 2019 & $1.47(1.16-1.79)$ & $0.0 \%(0.58)$ \\
\hline & $1.5(1.42,5.4)$ & Dadi et al [26] & 2014 & & \\
\hline & $2.1(1.2,3.7)$ & Geleta et al [27] & 2016 & & \\
\hline & $3.27(1.4,7.9)$ & Tegenu et al [28] & 2018 & & \\
\hline & 2.16(1.17,3.99 & Lenda et al [35] & 2018 & & \\
\hline & $1.35(0.3,0.99)$ & Sikolia et al [43] & 2002 & & \\
\hline \multirow[t]{7}{*}{ Caring of a child on mother during cooking } & $11.76(4.6,30.08)$ & Lema et al [24] & 2019 & $3.26(1.80-4.72)$ & $22.5 \%(0.26)$ \\
\hline & $5.38(2.13,9.65)$ & Fekadu et al [25] & 2014 & & \\
\hline & $1.7(1.317,7.362)$ & Dadi et al [26] & 2014 & & \\
\hline & $2.55(1.33,6.5)$ & Tegenu et al [28] & 2018 & & \\
\hline & $1.37(0.24,7.83)$ & Abuka et al [29] & 2017 & & \\
\hline & $7.37(2.55,21.32)$ & Tadesse et al [33] & 2015 & & \\
\hline & $6.2(3.25,11.83)$ & Lenda et al [35] & 2018 & & \\
\hline \multirow[t]{7}{*}{ Being unvaccinated } & $2.6(0.8,8.1)$ & Negash et al [22] & 2019 & $2.41(2.00-2.81)$ & $51.4 \%(0.055)$ \\
\hline & $1.6(0.9,2.9)$ & Geleta et al [27] & 2016 & & \\
\hline & $4.62(2.64,11)$ & Tegenu et al [28] & 2018 & & \\
\hline & $1.68(0.16,2.42)$ & Abuka et al [29] & 2017 & & \\
\hline & $2.77(0.19,0.54)$ & Workineh et al [30] & 2017 & & \\
\hline & $2.67(0.15,0.92)$ & MANYA et al [37] & 2005 & & \\
\hline & $1.68(0.16,2.42)$ & Onyango et al [39] & 2012 & & \\
\hline \multirow[t]{11}{*}{ Non-exclusive breast feeding } & $1.51(0.88,2.58)$ & Negash et al [22] & 2019 & $2.47(1.79,3.16)$ & $65.0 \%(0.01)$ \\
\hline & $6(3.33,10.8)$ & Abaye et al [23] & 2019 & & \\
\hline & $2.49(0.05,3.7)$ & Lema et al [24] & 2019 & & \\
\hline & $2(1.58,7.98)$ & Dadi et al [26] & 2014 & & \\
\hline & $3.3(2,5.4)$ & Geleta et al [27] & 2016 & & \\
\hline & $2.37(0.16,1.08)$ & Shibre et al [10] & 2015 & & \\
\hline & $3.3(1.27,8.3)$ & Tegenu et al [28] & 2018 & & \\
\hline & $4.2(1.07,16.6)$ & Abuka et al [29] & 2017 & & \\
\hline & $1.64(0.36,0.93)$ & Workineh et al [30] & 2017 & & \\
\hline & $6.10(2.5,14.93)$ & Markos et al [31] & 2019 & & \\
\hline & $8.33(2.6 .3,10.50)$ & Gedefaw et al [32] & 2015 & & \\
\hline \multirow[t]{5}{*}{ Child history of Acute Respiratory Tract infection (ARTI) } & $1.56(0.79,3.06)$ & Negash AA et al [22] & 2019 & $2.62(1.68,3.56)$ & $11.7 \%(0.337)$ \\
\hline & $1.36(0.26,7.21)$ & Abaye et al [23] & 2019 & & \\
\hline & $4.26(1.56,11.59)$ & Lema et al [24] & 2019 & & \\
\hline & $3.04(1.2,7.77)$ & Dadi et al [26] & 2014 & & \\
\hline & $5.2(3.1,8.9)$ & Geleta et al [27] & 2016 & & \\
\hline
\end{tabular}


Table 3 Factors associated with pneumonia in East Africa (Continued)

\begin{tabular}{lllll}
\hline Variables & Odds ratio(95\%Cl) & Author (reference) & Year & Pooled AOR(95\%Cl) \\
\hline & $4.03(2,8)$ & Tegenu et al [28] & 2018 \\
& $2.75(1.3,5.81)$ & Lenda et al [35] & 2018 \\
& $2.71(1.12,6.52)$ & Onyango et al [39] & 2012 \\
& $17.13(5.01,60.26)$ & Muthumbi et al [40] & 2017 \\
\hline
\end{tabular}

become 9. The pooled estimate of AOR of preterm becomes 1.406 (Supplementary Fig. 11). We employed a leave-one-out sensitivity analysis to identify the potential source of heterogeneity in the analysis of the pooled estimate of cooking food in living room as a risk factor of pneumonia in Eastern Africa. The results of this sensitivity analysis showed that our findings were not dependent on a single study. Our pooled estimate of cooking food in living room varied between $1.428(95 \% \mathrm{CI}, 1.102-$ $1.755)$ and $2.09(95 \% \mathrm{CI}, 1.314-2.875)$ after deletion of a single study (Supplementary Fig. 12).

\section{Caring of the child on mothers during cooking}

Seven studies found significant association between putting a child at the back during cooking and pneumonia among under five children. Of these the highest risk factors, $\mathrm{AOR}=11.76(4.6,30.08)$ Lema et al [24] and lowest risk factor $\mathrm{AOR}=1.37(0.24,7.83)$ Abuka et al [29] compared to those who didn't put their baby at their back (Table 3). Regarding heterogeneity test, Galbraith plot showed homogeneity and combining the result of seven studies the forest plot showed the overall estimate of AOR of pneumonia was $3.26\left(95 \% \mathrm{CI}: 1.80-4.72 ; \mathrm{I}^{2}=\right.$ $22.5 \% ; P=0.258)$.I-Squared $\left(\mathrm{I}^{2}\right)$ and $P$-value also showed homogeneity (Supplementary Fig. 13). Regarding test of publication bias a funnel plot showed a symmetrical distribution. Egger's regression test $p$-value was 0.074, which indicated the presence of publication bias (Supplementary Fig. 14). We employed a leave-one-out sensitivity analysis to identify the potential source of heterogeneity in the analysis of the pooled estimate of putting a child at the back during cooking as a risk factor of pneumonia in Eastern Africa. The results of this sensitivity analysis showed that our findings were not dependent on a single study. Our pooled estimate of putting a child at the back during cooking varied between $2.87(95 \% \mathrm{CI}$, 1.329-4.426) and 3.59(95\% CI, 1.828-5.355) after deletion of a single study (Supplementary Fig. 16).

\section{Being unvaccinated}

Seven studies found significant association between being unvaccinated and pneumonia among under five children. Of these the highest risk factors, $\mathrm{AOR}=4.62(2.64$, 11) Tegenu et al [28] and lowest risk factor $A O R=$ 1.6(0.9,2.9) Geleta et al [27] compared to those who have been vaccinated (Table 3 ). Regarding heterogeneity test,
Galbraith plot showed homogeneity and combining the result of seven studies, the forest plot showed the overall estimate of AOR of not being vaccinated was $2.41(95 \% \mathrm{C}$ I: $\left.2.00-2.81 ; \mathrm{I}^{2}=51.4 \% ; P=0.055\right)$.I-Squared $\left(\mathrm{I}^{2}\right)$ and $P$ value also showed homogeneity (Supplementary Fig. 17). Regarding publication bias, a funnel plot showed a symmetrical distribution. During the Egger's regression test, the $p$-value was 0.177 , which indicated the absence of publication bias (Supplementary Fig. 18). We employed a leave-one-out sensitivity analysis to identify the potential source of heterogeneity in the analysis of the pooled estimate of being unvaccinated as a risk factor of pneumonia in Eastern Africa. The results of this sensitivity analysis showed that our findings were not dependent on a single study. Our pooled estimate of being unvaccinated varied between $2.4(95 \% \mathrm{CI}, 2.07-2.72)$ and 2.71(95\%CI, 2.55-2.86) after deletion of a single study (Supplementary Fig. 19).

\section{Non-exclusive breast feeding}

Eleven studies found significant association between non-exclusive breast feeding and pneumonia among under five children. Of these the highest risk factors, $\mathrm{AOR}=8.33(2.6 .3,10.50)$ Gedefaw et al [32] and lowest risk factor AOR $=1.51(0.88,2.58)$ Negash et al [22] compared to those who breast feed exclusively (Table 3). Regarding heterogeneity test, Galbraith plot showed heterogeneity and combining the result of eleven studies, the forest plot showed the overall estimate of AOR of non-exclusive breast feeding was $2.47(95 \% \mathrm{C}$ I: $1.79,3.16$; $\left.\mathrm{I}^{2}=65.0 \% ; P=0.01\right) . \mathrm{I}$-Squared $\left(\mathrm{I}^{2}\right)$ and $P$-value also showed heterogeneity (Supplementary Fig. 20). Regarding publication bias, a funnel plot showed an asymmetrical distribution. During the Egger's regression test, the $p$-value was 0.016 , which indicated the presence of publication bias (Supplementary Fig. 21). Due to presence of publication bias trim and fill analysis was done and 5 studies were added, and the total number of studies becomes 16. The pooled estimate of AOR of nonexclusive breast feeding was found to be 2.05 (Supplementary Fig. 22). We employed a leave-one-out sensitivity analysis to identify the potential source of heterogeneity in the analysis of the pooled estimate of being non-exclusive breast feeding as a risk factor of pneumonia in Eastern Africa. The results of this sensitivity analysis showed that our findings were not dependent on a 
single study. Our pooled estimate of being for nonexclusive breast feeding is found to be between $1.757(95 \% \mathrm{CI}, 1.49-2.01)$ and $1.936(95 \% \mathrm{CI}, 1.70-2.17)$ after deletion of a single study (Supplementary Fig. 23).

\section{History acuter respiratory tract infection (ARTI)}

History ARTI was considered when a child has history of ARTI with in the 2 weeks before being diagnosed for pneumonia. Nine studies found significant association between history ARTI and pneumonia among under five children. Of these the highest risk factors, AOR = 17.13(5.01,60.26) Muthumbi et al [40] and lowest risk factor AOR $=1.36(0.26,7.21)$ Abaye et al [23] compared to those who use non wood item as a source of fuel (Table 3). Regarding heterogeneity test, Galbraith plot showed homogeneity and combining the result of nine studies, the forest plot showed the overall estimate of AOR of history ARTI was considered was $2.62(95 \% \mathrm{C}$ I: $\left.1.68,3.56 ; \mathrm{I}^{2}=11.7 \% ; P=0.337\right) . \mathrm{I}$-Squared $\left(\mathrm{I}^{2}\right)$ and $P$-value also showed homogeneity (Supplementary Fig. 24). Regarding publication bias, a funnel plot showed an asymmetrical distribution. During the Egger's regression test, the $p$-value was 0.024 , which indicated the presence of publication bias (Supplementary Fig. 25). Due to presence of publication bias trim and fill analysis was done and 5 studies were added, and the total number of studies becomes 14. The pooled estimate of AOR of history of ARTI was found to be 1.958(Supplementary Fig. 26).

We employed a leave-one-out sensitivity analysis to identify the potential source of heterogeneity in the analysis of the pooled estimate of being history of ARTI as a risk factor of pneumonia in Eastern Africa. The results of this sensitivity analysis showed that our findings were not dependent on a single study. Our pooled estimate of having history of ARTI ranges between 2.195(95\%CI, $1.36-3.02)$ and $3.28(95 \% \mathrm{CI}, 2.153-4.417)$ after deletion of a single study (Supplementary Fig. 27).

\section{Discussion}

This systematic review and meta-analysis was conducted to assess the magnitude of pneumonia and its associated factors among under-five children in East Africa. Thirtyfour studies were included for the final analysis. Twentytwo studies had reported the prevalence of pneumonia and the pooled prevalence of pneumonia in under-five children was found to be $34 \%$ with $95 \%$ CI of (23.844.21\%). This result was higher than a study conducted in Dibrugarh, India which had reported the prevalence of pneumonia in under-five children to be 16.34\% [9]. This might be due to socioeconomic and seasonal discrepancies as countries in East Africa are less developed than India. A study conducted in Nigeria had revealed the prevalence of pneumonia in under-five children to be $31.6 \%$ which was consistence with the findings of this systematic review [53]. This consistency might be due to similarities in socio-economic status as Nigeria is an African country probably having comparable socio-economic status with east African countries. In addition the discrepancy might be due to difference in case definition of pneumonia.

This finding is higher than other studies done in Austria (4.1\%) [54], in Mali (6.7\%) [55], and in Bangladesh (21.3\%) [56]. This variation might be due to socio-economic and socio-demographic vitiations, the variation in the study setting, seasonal variation, unreachability and provision of Vitamin A supplementation and immunization, lack of confirmatory laboratories and imaging investigations.

This systematic review and meta-analysis had also revealed using woods as a source of fuel, cooking foods living rooms, holding children on back while cooking foods, being unvaccinated, history of being not on exclusive breast feeding, history of upper respiratory tract infection and parental smoking as a significant risk factors for increased prevalence of pneumonia among underfive children in East Africa.

Higher odds of pneumonia were observed in underfive children whose family uses wood as a source of fuel. This result was in line with studies conducted in India [57], and Sri Lanka [58]; and with systematic reviews conducted in Low and Middle income countries [59], and Africa, China and Latin America [60]. It was also consistent with a global review conducted by Jackson et al. [61]. The association between using wood as a source of fuel and pneumonia in under-five children might be due to the fact that using woods as a source of fuel results in release of wood smokes containing major air pollutants like carbon monoxide and particulate matters which causes indoor air pollution [62]. Indoor air pollution and inhaling wood smoke in turn impairs the function of pulmonary alveolar macrophages and epithelial cells which will increase the likelihood of pulmonary infections including pneumonia [62, 63].

According to this systematic review and meta-analysis, cooking foods in living rooms was found to be significantly associated with occurrence of pneumonia in under-five children as higher odds of pneumonia was exhibited among children living in families who cooks food at living rooms than children living in families who cooks food in kitchen. Holding children on back while cooking foods was another factor found to be significantly associated with pneumonia. This association might be due to the reason that cooking foods in living rooms will cause indoor air pollution and holding a child on back while cooking foods can increase the probability of inhaling smokes and food vapors (steams) which in turn will increase the risk of acquiring pneumonia by 
altering the structure and function of the respiratory tract $[58,63]$.

In this systematic review children with history of Acute Respiratory Tract Infections (ARTIs) were found to be at increased risk to acquire pneumonia; as the odds of pneumonia among children who had history of ARTIs was higher than children without history of ARTIs. The reason behind this association might be due to the fact that ARTIs will alter the structure and function of the respiratory tract and can cause Lower Respiratory Infections (LRTIs) including pneumonia in two ways- by increasing invasion of the Lower respiratory tract (LRT) with other microorganisms which cause secondary infections or by progressive invasion of LRT with the same microorganism causing the ARTIs (Primary infections) [64].

The risk of acquiring pneumonia in unvaccinated children was found to be higher than vaccinated children. This result was similar with studies conducted in Brazil [65], Bellary [7], and India [66]. A systematic review conducted by Jackson et al. [61] was also in line with this result. Similarly, children who were not on exclusive breast feeding were at higher risk to develop pneumonia than children who were on exclusive breast feeding for the first 6 months of age. This result was consistent with different studies conducted across the world $[7,61,67,68]$. The reason behind this association might be due to low or weak immunity. Because exclusive breast feeding and vaccination are strategies used to increase the immunity of children and prevent childhood infections. So, children who were not on Exclusive breast feeding and/ or unvaccinated will have weak immunity and increased probability of acquiring infections including pneumonia [69].

\section{Strength and limitations}

This study has several strengths: First, we used a prespecified protocol for search strategy and data abstraction and used internationally accepted tools for a critical appraisal system for quality assessment of individual studies. Second, we employed subgroup and sensitivity analysis based on study country, study design, and publication year to identify the small study effect and the risk of heterogeneity. Nevertheless, this review had some limitations: There may be publication bias because not all grey literature was included and language biases since all included studies are published in English.

\section{Conclusion and recommendation}

The prevalence of pneumonia among under-five children in Eastern Africa remains high. Use of wood as fuel source, cooking food in living room, caring of a child on mother during cooking, being unvaccinated, onexclusive breast feeding,child history of ARTI, and parental smoking were independent potential predictors of under-five pneumonia in Eastern Africa. Hence, appropriate intervention on potential determinates such as health education on exclusive breastfeeding, place of food cooking, increase vaccination coverage and early control of respiratory tract infection was recommended to prevent those risk factors.

\section{Supplementary information}

Supplementary information accompanies this paper at https://doi.org/10. 1186/s12887-020-02083-z.

\section{Additional file 1. PRISMA 2009 Checklist}

Additional file $\mathbf{2}$ Supplementary Figure 1. Forest plot showing subgroup analysis (by country) of pooled prevalence of pneumonia among under-five children in Ethiopia from2002 up to 2019. Supplementary Figure $\mathbf{2}$. Forest plot showing subgroup analysis (by study design) of pooled prevalence of pneumonia among under-five children in Ethiopia from2002 up to 2019. Supplementary Figure 3. Forest plot showing subgroup analysis (by country) of pooled prevalence of pneumonia among under-five children in Ethiopia from2002 up to 2019. Supplementary Figure 4. sensitivity of pooled prevalence of pneumonia among under-five children in Ethiopia from2002 up to 2019. Supplementary Figure 5. publication bias of pooled prevalence of pneumonia among under-five children in Ethiopia from2002 up to 2019. Supplementary Figure $\mathbf{6}$. Forest plot showing of pooled estimate of AOR for using wood as fuel source as a predictor of pneumonia among underfive children in Ethiopia from2002 up to 2019. Supplementary Figure 7. publication bias of pooled estimate of AOR for using wood as fuel source as a predictor of pneumonia among under-five children in Ethiopia from2002 up to 2019. Supplementary Figure 8. sensitivity analysis of pooled estimate of AOR for using wood as fuel source as a predictor of pneumonia among under-five children in Ethiopia from2002 up to 2019. Supplementary Figure 9: Forest plot showing the pooled estimate of AOR for cooking food at home as a predictor of pneumonia among under-five children in Ethiopia from2002 up to 2019.Supplementary Figure 10. publication bias for pooled estimate of AOR for cooking food at home as a predictor of pneumonia among under-five children in Ethiopia from2002 up to 2019. Supplementary Figure 11. Trim and fill analysis for pooled estimate of AOR for cooking food at home as a predictor of pneumonia among under-five children in Ethiopia from2002 up to 2019. Supplementary Figure 12. Sensitivity analysis for pooled estimate of AOR for cooking food at home as a predictor of pneumonia among under-five children in Ethiopia from2002 up to 2019. Supplementary Figure 13. Forest plot showing estimate of $A O R$ for caring of the child on mothers during cooking as a predictor of pneumonia among under-five children in Ethiopia from2002 up to 2019. Supplementary Figure 14. publication bias for estimate of AOR for caring of the child on mothers during cooking as a predictor of pneumonia among under-five children in Ethiopia from2002 up to 2019. Supplementary Figure 15. trim and fill analysis for estimate of AOR for caring of the child on mothers during cooking as a predictor of pneumonia among under-five children in Ethiopia from2002 up to 2019. Supplementary Figure 16. sensitivity analysis for estimate of AOR for caring of the child on mothers during cooking as a predictor of pneumonia among under-five children in Ethiopia from2002 up to 2019. Supplementary Figure 17. Forest plot showing the pooled estimate of $A O R$ for being unvaccinated as a predictor of pneumonia among under-five children in Ethiopia from2002 up to 2019. Supplementary Figure 18 publication bias for pooled estimate of AOR for being unvaccinated as a predictor of pneumonia among under-five children in Ethiopia from2002 up to 2019. Supplementary Figure 19. sensitivity analysis for pooled estimate of AOR for being unvaccinated as a predictor of pneumonia among under-five children in Ethiopia from2002 up to 2019. Supplementary Figure $\mathbf{2 0}$. Forest plot showing the pooled estimate of $A O R$ for non-exclusive breast feeding as a predictor of pneumonia among under-five children in Ethiopia from 2002 up to 2019. Supplementary 
Figure 21. publication bias for the pooled estimate of AOR for nonexclusive breast feeding as a predictor of pneumonia among under-five children in Ethiopia from 2002 up to 2019. Supplementary Figure 22. Trim and fill analysis for the pooled estimate of AOR for non-exclusive breast feeding as a predictor of pneumonia among under-five children in Ethiopia from 2002 up to 2019. Supplementary Figure 23. Sensitivity analysis for the pooled estimate of AOR for non-exclusive breast feeding as a predictor of pneumonia among under-five children in Ethiopia from 2002 up to 2019. Supplementary Figure 24. Forest plot showing the pooled estimate of AOR for history of ARTI as a predictor of pneumonia among under-five children in Ethiopia from 2002 up to 2019. Supplementary Figure 25. Publication bias for the pooled estimate of AOR for history of ARTI as a predictor of pneumonia among under-five children in Ethiopia from 2002 up to 2019. Supplementary Figure 26. Trim and fill analysis for the pooled estimate of AOR for history of ARTI as a predictor of pneumonia among under-five children in Ethiopia from 2002 up to 2019. Supplementary Figure $\mathbf{2 7}$. sensitivity analysis for the pooled estimate of AOR for history of ARTI as a predictor of pneumonia among under-five children in Ethiopia from 2002 up to 2019

Additional file $\mathbf{3}$ Table $\mathbf{S 1}$. Search strategy used for one of the databases

Additional file 4 Table S2. Quality appraisal result of included studies in East Africa, from 2002 to 2019. Using Joanna Briggs Institute (JBI) quality appraisal checklist

Additional file $\mathbf{5}$ Table S3. Adjusted confounders and main findings extracted from included studies in East Africa

\section{Abbreviations}

Cl: Confidence Interval; OR: Odds Ratio; U5M: Under Five Mortalities; WHO: World Health Organization; DHS: Demographic and Health Surveys; EDHS: Ethiopian Demographic and Health Survey; AOR: Adjusted odds ratio; ARTI: Acute Respiratory Tract Infections

\section{Acknowledgments}

We would like to thank the primary authors of the included studies.

\section{Authors' contributions}

$\mathrm{BB}, \mathrm{MB}, \mathrm{MA}, \mathrm{AM}$ and $\mathrm{MW}$ : developed the study design and protocol, literature review, selection of studies, quality assessment, data extraction, statistical analysis, interpretation of the data and developing the initial drafts of the manuscript and prepared the final draft of the manuscript. All authors read and approved the final manuscript.

\section{Funding}

No funding was obtained for this study.

\section{Availability of data and materials}

The datasets analyzed during the current study are available from the corresponding author upon reasonable request.

\section{Ethics approval and consent to participate}

Not applicable.

\section{Consent for publication}

Not applicable.

\section{Competing interests}

We have confirmed that we have no competing interests.

Received: 5 February 2020 Accepted: 13 April 2020

Published online: 27 May 2020

\section{References}

1. Mackenzie G. The definition and classification of pneumonia. Pneumonia. 2016;8(1):14.

2. WHO. Revised WHO classification and treatment of childhood pneumonia at health facilities. WHO. 2014.

3. Kalii AC, Metersky ML, Klompas M, Muscedere J, Sweeney DA, Palmer LB, et al. Management of adults with hospital-acquired and ventilator- associated pneumonia: 2016 clinical practice guidelines by the Infectious Diseases Society of America and the American Thoracic Society. Clin Infect Dis. 2016;63(5):e61-e111.

4. McAllister DA, Liu L, Shi T, Chu Y, Reed C, Burrows J, et al. Global, regional, and national estimates of pneumonia morbidity and mortality in children younger than 5 years between 2000 and 2015: a systematic analysis. Lancet Glob Health. 2019;7(1):e47-57.

5. Rudan I, Boschi-Pinto C, Biloglav Z, Mulholland K, Campbell H. Epidemiology and etiology of childhood pneumonia. Bull World Health Organ. 2008;86: 408-16B.

6. Ramezani M, Aemmi SZ, Emami MZ. Factors affecting the rate of pediatric pneumonia in developing countries: a review and literature study. Int J Pediatr. 2015:3(6.2):1173-81.

7. Hemagiri K, Sameena A, Aravind K, Khan W, Vasanta S. Risk factors for severe pneumonia in under five children — a hospital based study. Int J Res Health Sci. 2014;2(1):47-57.

8. Htar MTT, Stuurman AL, Ferreira G, Alicino C, Bollaerts K, Paganino C, et al. Effectiveness of pneumococcal vaccines in preventing pneumonia in adults, a systematic review and meta-analyses of observational studies. Plos One. 2017;12(5).

9. Nirmolia N, Mahanta TG, Boruah M, Rasaily R, Kotoky RP, Bora R. Prevalence and risk factors of pneumonia in under five children living in slums of Dibrugarh town. Clin Epidemiol Glob Health. 2018;6(1):1-4.

10. Shibre G. Assessment of the Prevalence and associated factors of pneumonia in children 2to 59 months old, Debreberhan District, North East Ethiopia: Addis Abeba University; 2015.

11. Ásbjörnsdóttir KH, Slyker JA, Weiss NS, Mbori-Ngacha D, Maleche-Obimbo E, Wamalwa $\mathrm{D}$, et al. Breastfeeding is associated with decreased pneumonia incidence among HIV-exposed, uninfected Kenyan infants. AIDS (London, England). 2013;27(17):2809.

12. Peters MD, Godfrey CM, Mclnerney P, Soares CB, Khalil H, Parker D. The Joanna Briggs institute reviewers' manual 2015: methodology for JBI scoping reviews. 2015.

13. Institute JB. Meta-analysis of statistics: assessment and review instrument (JBI mastari). Adelaide. 2006;20032007.

14. Elfving K, Shakely D, Andersson M, Baltzell K, Ali AS, Bachelard M, et al. Acute uncomplicated febrile illness in children aged 2-59 months in Zanzibar-Aetiologies, antibiotic treatment and outcome. PloS One. 2016; $11(1)$

15. Jiskani FB, Shaikh F, Syal AR, Nizamani MA, Shaikh MA. X-ray CHEST findings in children aged 2 months to 59 months classified as pneumonia ACCORDING to IMNCI guidelines. Pak Armed Forces Med J. 2017;67(5):779-82.

16. Borenstein $M$, Hedges LV, Higgins JP, Rothstein HR. A basic introduction to fixed-effect and random-effects models for meta-analysis. Res Synth Methods. 2010;1 (2):97-111

17. Higgins JP, Thompson SG, Deeks JJ, Altman DG. Measuring inconsistency in meta-analyses. BMJ. 2003;327(7414):557-60.

18. Ioannidis JP. Interpretation of tests of heterogeneity and bias in metaanalysis. J Eval Clin Pract. 2008;14(5):951-7.

19. Higgins JP, Thompson SG. Quantifying heterogeneity in a meta-analysis. Stat Med. 2002;21(11):1539-58.

20. Egger M, Smith GD, Schneider M, Minder C. Bias in meta-analysis detected by a simple, graphical test. BMJ. 1997;315(7109):629-34.

21. Shah $\mathrm{S}$, Zemichael O, Meng HD. Factors associated with mortality and length of stay in hospitalised neonates in Eritrea, Africa: a cross-sectional study. BMJ Open. 2012;2(5):e000792.

22. Negash AA, Asrat D, Abebe W, Hailemariam T, Hailu T, Aseffa A, et al., editors. Bacteremic community-acquired pneumonia in Ethiopian children: etiology, antibiotic resistance, risk factors, and clinical outcome. Open forum infectious diseases; 2019: Oxford University Press US.

23. Abaye G, Fekadu H, Haji K, Alemu D, Anjulo AA, Yadate DT. Prevalence and risk factors of pneumococcal nasopharyngeal carriage in healthy children attending kindergarten, in district of Arsi zone, south east, Ethiopia. BMC Res Notes. 2019;12(1):253.

24. Lema B, Seyoum K, Atlaw D. Prevalence of community acquired pneumonia among children 2 to 59 months old and its associated factors in Munesa District, Arsi zone, Oromia region. Ethiop Clin Mother Child Health. 2019;16:334

25. Fekadu GA, Terefe MW, Alemie GA. Prevalence of pneumonia among under-five children in Este town and the surrounding rural Kebeles, 
Northwest Ethiopia: a community based cross sectional study. Sci J Public Health. 2014;2(3):150-5.

26. Dadi AF, Kebede $Y$, Birhanu Z. Determinants of pneumonia in children aged two months to five years in urban areas of Oromia zone, Amhara region. Ethiop Open Access Library J. 2014;1 (08):1.

27. Geleta D, Tessema F, Ewnetu H. Determinants of community acquired pneumonia among children in Kersa District, Southwest Ethiopia: facility based case control study. J Pediatr Neonatal Care. 2016;5(2):00179.

28. Tegenu K. Prevalence and associated factors of pneumonia among underfive children at public hospitals in Jimma zone, South West of Ethiopia, 2018: Addis Ababa Universty; 2018.

29. Abuka T. Prevalence of pneumonia and factors associated among children 2-59 months old in Wondo genet district, Sidama zone, SNNPR, Ethiopia. Current Pediatric Research. 2017.

30. Workineh Y, Hailu D, Gultie T. Determinants of pneumonia among under two children in southern Ethiopia: A case control study 2016. Curr Pediatr Res. 2017;21(4).

31. Markos Y, Dadi AF, Demisse AG, Ayanaw Habitu Y, Derseh BT, Debalkie G. Determinants of under-five pneumonia at Gondar University hospital, Northwest Ethiopia: an unmatched case-control study. J Environ Public Health. 2019;2019.

32. Gedefaw M, Berhe R. Determinates of childhood pneumonia and diarrhea with special emphasis to exclusive breastfeeding in north Achefer district, Northwest Ethiopia: a case control study. Open J Epidemiol. 2015;5(02):107.

33. Tadesse R. Household biomass fuel use and acute respiratory infections among younger children: an exposure assessment in Anilemo Woreda. Southern Ethiopia: Addis Ababa University; 2015.

34. Adhanom G, Gebreegziabiher D, Weldu Y, Gebreyesus Wasihun A, Araya T, Legese $\mathrm{H}$, et al. Species, risk factors, and antimicrobial susceptibility profiles of bacterial isolates from HIV-infected patients suspected to have pneumonia in Mekelle zone, Tigray, northern Ethiopia. Biomed Res Int 2019; 2019.

35. Lenda A, Demena M, Mengistie B. Prevalence of pneumonia and associated factors among under-five children in Boloso bombe Woreda, southern Ethiopia: a community based study: Haramaya University; 2018.

36. Deribew A, Tessema F, Girma B. Determinants of under-five mortality in Gilgel gibe field research center, Southwest Ethiopia. Ethiop J Health Dev. 2007;21(2):117-24.

37. MANYA AS. Risk factors for pneumonia in children under five years of age, HOSPITALIZED IN A RURAL DISTRICT HOSPITAL OF WESTERN KENYA, 2005.

38. Keter PKK. Knowledge, attitudes and practices of mothers in relation to childhood pneumonia and factors associated with pneumonia and seeking health Care in Kapsabet District Hospital in Nandi County. Kenya: JKUAT; 2015.

39. Onyango D, Kikuvi G, Amukoye E, Omolo J. Risk factors of severe pneumonia among children aged 2-59 months in western Kenya: a case control study. Pan Afr Med J. 2012;13(1).

40. Muthumbi E, Lowe BS, Muyodi C, Getambu E, Gleeson F, Scott JAG. Risk factors for community-acquired pneumonia among adults in Kenya: a casecontrol study. Pneumonia. 2017;9(1):17.

41. Ndungu EW, Okwara FN, Oyore JP. Cross sectional survey of care seeking for acute respiratory illness in children under 5 years in rural Kenya. Am J Pediatr. 2018:4(3):69-79.

42. Walekhwa M, Muturi M, Revathi Gunturu EK, Kabera B. Streptococcus pneumoniae serotype epidemiology among PCV-10 vaccinated and unvaccinated children at Gertrude's Children's Hospital, Nairobi County: a cross-sectional study. F1000Research. 2018;7.

43. 角井, 信弘. The prevalence of acute respiratory infections and the associated risk factors: a study of children under five years of age in Kibera Lindi village, Nairobi, Kenya. J Natl Inst Public Health. 2002;51:1.

44. Kinyoki DK, Manda SO, Moloney GM, Odundo EO, Berkley JA, Noor AM, et al. Modelling the ecological comorbidity of acute respiratory infection, diarrhoea and stunting among children under the age of 5 years in Somalia. Int Stat Rev. 2017:85(1):164-76.

45. Gritly SM, Elamin MO, Rahimtullah H, Ali AYH, Dhiblaw A, Mohamed EA, et al. Risk factors of pneumonia among children under 5 years at a pediatric hospital in Sudan. Int J Med Res Health Sci. 2018;7(4):60-8.

46. Salih KEM, Bilal JA, Alfadeel MA, Hamid Y, Eldouch W, Elsammani E, et al. Poor adherence to the World Health Organization guidelines of treatment of severe pneumonia in children at Khartoum, Sudan. BMC Res Notes. 2014; 7(1):531.
47. Gabbad AA, Alrahman GMA, Elawad MA. Childhood pneumonia at Omdurman paediatric hospital, Khartoum, Sudan. Int J of Multidisciplinary and Current research. 2014.

48. Deng AA. Risk factors for acute lower respiratory tract infections in children under five years of age in juba. Southern Sudan: JKUAT-COHES; 2019.

49. Ndosa A, Kidenya BR, Mushi MF, Mirambo MM, Hokororo A, Mshana SE. Factors associated with colonization of Streptococcus pneumoniae among under-fives attending clinic in Mwanza City, Tanzania. Tanzan J Health Res. 2015;17(1).

50. Lugangira K, Kalokola F. Morbidity and mortality of children aged 2-59 months admitted in the Tanzania Lake Zone's public hospitals: a crosssectional study. BMC Res Notes. 2017;10(1):502.

51. Lindstrand A, Kalyango J, Alfven T, Darenberg J, Kadobera D, Bwanga F, et al. Pneumococcal carriage in children under five years in Uganda-will present pneumococcal conjugate vaccines be appropriate? PloS one. 2016; 11(11).

52. Tuhebwe $\mathrm{D}$, Tumushabe E, Leontsini E, Wanyenze RK. Pneumonia among children under five in Uganda: symptom recognition and actions taken by caretakers. Afr Health Sci. 2014;14(4):993-1000.

53. Ujunwa F, Ezeonu C. Risk factors for acute respiratory tract infections in under-five children in Enugu Southeast Nigeria. Ann Med Health Sci Res. 2014;4(1):95-9.

54. Kurz H GH, Huber K, Krugluger W, Asbott F, Wabnegger $L$, Apfalter $P$, Sebesta, C. Spectrum of pathogens of in-patient children and youths with community acquired pneumonia: a 3 year survey of a community hospital in Vienna, Austria. Wiener klinische Wochenschrift 2013, 125(21-22):674-679. 2013.

55. Bénet T SM, Messaoudi M, Picot VS, Telles J-N, Diakite A-A, Komurian-Pradel

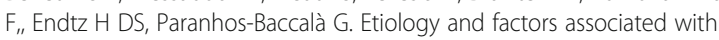
pneumonia in children under 5 years of age in Mali: a prospective casecontrol study. PloS one 2015, 10(12):e0145447. 2015.

56. KMAK A. Risk factors for acute respiratory infections (ARI) among under five children in Bangladesh. J Sci Res 2009, 1(1):72-81. 2009.

57. Kankaria A, Nongkynrih B, Gupta SK. Indoor air pollution in India: implications on health and its control. Ind J Commun Med. 2014;39(4):203.

58. Ranathunga N, Perera P, Nandasena S, Sathiakumar N, Kasturiratne A, Wickremasinghe R. Effect of household air pollution due to solid fuel combustion on childhood respiratory diseases in a semi urban population in Sri Lanka. BMC Pediatr. 2019;19(1):306.

59. Adaji EE, Ekezie W, Clifford M, Phalkey R. Understanding the effect of indoor air pollution on pneumonia in children under 5 in low-and middle-income countries: a systematic review of evidence. Environ Sci Pollut Res. 2019;26(4): 3208-25.

60. Dherani M, Pope D, Mascarenhas M, Smith KR, Weber M, Bruce N. Indoor air pollution from unprocessed solid fuel use and pneumonia risk in children aged under five years: a systematic review and meta-analysis. Bull World Health Organ. 2008:86:390-8C.

61. Jackson S, Mathews KH, Pulanić D, Falconer R, Rudan I, Campbell H, et al. Risk factors for severe acute lower respiratory infections in children-a systematic review and meta-analysis. Croatian Med J. 2013;54(2):110-21.

62. Chafe Z, Brauer M, Héroux M-E, Klimont Z, Lanki T, Salonen RO, et al. Residential heating with wood and coal: health impacts and policy options in Europe and North America. 2015.

63. Cardani A, Boulton A, Kim TS, Braciale TJ. Alveolar macrophages prevent lethal influenza pneumonia by inhibiting infection of type-1 alveolar epithelial cells. PLoS Pathog. 2017;13(1):e1006140.

64. Thomas M, Bomar PA. Upper respiratory tract infection. StatPearls [Internet]: StatPearls Publishing; 2019

65. da Fonseca Lima EJ, Mello MJG, Lopes MIL, Serra GHC, Lima DEP, Correia JB. Risk factors for community-acquired pneumonia in children under five years of age in the post-pneumococcal conjugate vaccine era in Brazil: a case control study. BMC Pediatr. 2016;16(1):157.

66. Gothankar J, Doke P, Dhumale G, Pore P, Lalwani S, Quraishi S, et al. Reported incidence and risk factors of childhood pneumonia in India: a community-based cross-sectional study. BMC Public Health. 2018;18(1):1-11.

67. Horta BL, Victora CG, Organization WH. Short-term effects of breastfeeding: a systematic review on the benefits of breastfeeding on diarrhoea and pneumonia mortality. 2013.

68. Lamberti LM, Zakarija-Grković I, Walker CLF, Theodoratou E, Nair H, Campbell $\mathrm{H}$, et al. Breastfeeding for reducing the risk of pneumonia 
morbidity and mortality in children under two: a systematic literature review and meta-analysis. BMC Public Health. 2013;13(S3):S18.

69. Alasil S, Kutty P. Breastfeeding as a tool that empowers infant immunity through maternal vaccination. J Vaccines Vaccin. 2015;6(271):2.

\section{Publisher's Note}

Springer Nature remains neutral with regard to jurisdictional claims in published maps and institutional affiliations.

Ready to submit your research? Choose BMC and benefit from:

- fast, convenient online submission

- thorough peer review by experienced researchers in your field

- rapid publication on acceptance

- support for research data, including large and complex data types

- gold Open Access which fosters wider collaboration and increased citations

- maximum visibility for your research: over $100 \mathrm{M}$ website views per year

At $\mathrm{BMC}$, research is always in progress.

Learn more biomedcentral.com/submissions 